DOI: $10.15593 / 2224-9354 / 2019.2 .19$

УДК 378.091

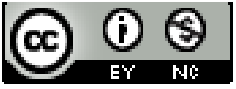

\title{
Д.В. Попов
}

\section{ЛОГИКА МЕТОДИК ОЦЕНКИ ЭФФЕКТИВНОСТИ ДЕЯТЕЛЬНОСТИ ВУЗОВ}

\begin{abstract}
C переходом в постиндустриальное общество успех в долгосрочном социально-экономическом развитии страны во многом определяется результатами деятельности высших учебных заведений и, прежде всего, результатами их финансово-экономической деятельности. В настоящее время существует много различных методик оценки эффективности деятельности вузов РФ, но ни одна из них не дает полной и достоверной информации о результатах их фринансовоэкономической деятельности. Основной причиной этого, на наш взгляд, является чрезмерное обобщение логики методик оценки эффективности деятельности вузов РФ, без учета специфики ведения деятельности вузов различных типов, которая определяется разностью моделей их фринансирования. В статье проведен анализ логики методик оценки эффективности деятельности вузов РФ, в процессе которого мы определили: предельный и допустимый уровень обобщения объекта наблюдения в методиках оценки и допустимые объекты исследования методик оценки. В настоящее время в научной литературе РФ нет ни одной методики оценки, способной полно и достоверно оценить финансово-экономическую деятельность вузов РФ, так как эта методика должна представлять собой, как минимум, синтез трех методик оценки: методики оценки финансово-экономической деятельности государственных казенных вузов, методики оценки финансово-экономической деятельности государственных бюджетных и автономных вузов и методики оценки фринансово-экономической деятельности негосударственных вузов, которых также сейчас нет в научной литературе РФ.

Ключевые слова: высшее образование, логика методики оценки, объект наблюдения, объект исследования, мониторинг вузов, фринансовое регулирование, эффрективность вузов, бюджетное учреждение, автономное учреждение, финансово-экономическая деятельность.
\end{abstract}

Введение. Социально-экономическое развитие в XXI веке характеризуется возрастающей ролью человеческого капитала, наиболее продуктивная и активная часть которого формируется системой высшего образования [1].

Осуществляя финансовое регулирование социальных и экономических процессов в вузах, государство и высший менеджмент вузов оказывают целенаправленное влияние на структуру человеческого капитала и его активность, тем самым определяя и стимулируя отдельные направления социально-экономического развития государства [2].

Для осуществления контроля над реализацией изменений в социальных и экономических процессах вузов путем финансового регулирования этих процессов необходима достоверная, компактная и одновременно достаточная для оценки структурированная информация, источником которой должен стать мониторинг деятельности вузов [3].

(C) Попов Д.В., 2019

Попов Дмитрий Викторович - ассистент кафедры финансового рынка и финансовых институтОВ ФГБОУ ВО «Новосибирский государственный университет экономики и управления «HИHX», e-mail: dmit-popov@yandex.ru. 
Существуют сотни научных работ, посвященных вопросам методики оценки эффективности деятельности вузов. Исследованию этих вопросов посвятили свои труды Д. Амирова, И. Богомолова, Я. Бондарев, С. Борисова, М. Боровская, Р. Булатова, Т. Василишин, А. Галимова, О. Григораш, С. Гриненко, И. Гришунина, С. Данилова, О. Донец, М. Егорихина, Е. Задорожная, Ю. Ирхин, М. Казаковцева, С. Кара-Мурза, О. Кичигина, С. Козлов, И. Костенко, А. Кузнецова, Ю. Кудряшова, М. Кулакова, М. Курдова, О. Латуха, Е. Левашов, С. Марков, Э. Насибова, Г. Резник, Г. Сабырова, Н. Саяпина, О. Семикин, Г. Сироткин, В. Сухочев, Ю. Тугуз, Н. Филин, Е. Чекотило, М. Чистилина, И. Шевченко, Н. Яшина.

Однако, несмотря на то, что в некоторых методиках для оценки эффективности деятельности вузов используются отдельные показатели их финансовой деятельности, ни одна из представленных методик оценки не дает полной и достоверной информации, причиной чему является чрезмерное обобщение логики методик оценки эффективности деятельности вузов.

С целью определения допустимого уровня обобщения логики методик оценки эффективности деятельности вузов:

- определим допустимый уровень обобщения объекта наблюдения в методиках оценки эффективности деятельности вузов;

- проведем анализ объектов наблюдения современных методик оценки эффективности деятельности вузов;

- проведем анализ объектов исследования современных методик оценки эффективности деятельности вузов.

Объектом наблюдения нашего исследования являются учреждения высшего образования Российской Федерации.

Объектом исследования являются методики оценки эффективности деятельности учреждений высшего образования Российской Федерации (далее методики оценки).

Предметом исследования - методы построения логики методик оценки эффективности деятельности учреждений высшего образования Российской Федерации.

В работе используются следующие методы научного познания: метод сравнения, классификаций, статистические методы, метод экспертных оценок.

\section{1. Объект наблюдения методики оценки.}

1.1. Допустимый уровень обобщения объекта наблюдения в методиках оценки. В работе [4] нами подробно рассмотрена структура национальной системы высшего образования РФ и выделено 4 типа высших учреждений РФ: негосударственные высшие учебные заведения, государственные казенные высшие учебные заведения, государственные бюджетные высшие учебные заведения и государственные автономные высшие учебные заведения. Каждому типу свойственны свои специфические особенности организации 
и ведения деятельности, определенные на законодательном уровне, но в силу исторических особенностей реформирования национальной системы высшего образования РФ государственные бюджетные и автономные вузы существенно отличаются от негосударственных вузов и от государственных казенных вузов и во многом схожи между собой.

При оценке эффективности деятельности вузов РФ необходимо учитывать модели их финансирования. Для вузов национальной системы высшего образования РФ свойственны три модели финансирования: модель финансирования негосударственных учреждений, затратная модель финансирования и модель финансирования, ориентированная на конечный результат. Модель финансирования определяет специфику ведения деятельности для объекта финансирования, поэтому обобщать объекты наблюдения, имеющие различные модели финансирование, недопустимо (табл. 1).

Таблица 1

Модели финансирования вузов РФ

\begin{tabular}{|c|c|c|c|}
\hline \multirow{3}{*}{ Типы вузов РФ } & \multicolumn{3}{|c|}{ Вузы РФ } \\
\hline & \multicolumn{2}{|c|}{ государственные } & \multirow{2}{*}{ негосударственные } \\
\hline & казенные & \begin{tabular}{|l|l|} 
бюджетные & автономные \\
\end{tabular} & \\
\hline $\begin{array}{c}\text { Модели финанси- } \\
\text { рования }\end{array}$ & $\begin{array}{l}\text { Затратная модель } \\
\text { финансирования }\end{array}$ & \begin{tabular}{|c} 
Модель финансирования, \\
ориентированная на ко- \\
нечный результат
\end{tabular} & $\begin{array}{l}\text { Модель финансиро- } \\
\text { вания негосударст- } \\
\text { венных учреждений }\end{array}$ \\
\hline
\end{tabular}

Таким образом, в качестве объектов наблюдения методики оценки эффективности деятельности вузов национальной системы высшего образования РФ могут быть рассмотрены:

- государственные казенные вузы;

- государственные бюджетные и автономные вузы;

- негосударственные вузы;

- более мелкие в их составе группы.

1.2. Анализ объектов наблюдения современных методик оценки. Первые методики оценки появились в России в 2012 году, после вступления в силу 1 января 2012 года Федерального закона № 83-Ф3, который инициировал переход государственных вузов от затратной модели финансирования к модели финансирования, ориентированной на конечный результат [5].

В связи с этим объектом наблюдения первых методик оценки стали государственные вузы. В качестве примеров можно привести методики оценки: М.Н. Кулаковой [6], С.Н. Маркова [7], Г.Ж. Сабыровой [8]. Авторы этих методик оценки решают вопрос справедливого распределения государственных средств между государственными вузами, с учетом конечного результата от их использования. 
По мере развития национальной системы высшего образования РФ государственные бюджетные и автономные вузы (которые составляют 99 \% государственных вузов РФ) рассматриваются государством, наряду с негосударственными вузами, как полноценные участники рыночных отношений. При этом в рамках реализации Федеральной целевой программы развития образования на 2011-2015 годы государство стремится создать усовершенствованную национальную систему высшего образования РФ, которая будет состоять только из эффективных участников рыночных отношений $[9,10]$.

Изменения практических потребностей в оценке вузов способствуют появлению новых методик оценки, объектом наблюдения в которых являются вузы РФ (табл. 2). В качестве примеров можно привести методики оценки: М.А. Боровской, Е.К. Задорожной, И.К. Шевченко [11]; О.В. Григораш [12]; Г.Ж. Сабыровой [13]; Г.В. Сироткина [14]; методику мониторинга Минобрнауки РФ [16].

Таблица 2

Объекты наблюдения в методиках оценки эффективности деятельности вузов РФ

\begin{tabular}{|c|c|c|c|}
\hline \multirow[b]{2}{*}{$\begin{array}{c}\text { Существующие методики } \\
\text { оценки }\end{array}$} & \multicolumn{3}{|c|}{ Допустимый уровень обобщения объекта наблюдения } \\
\hline & $\begin{array}{c}\text { Государствен- } \\
\text { ные казенные } \\
\text { вузы } \\
\end{array}$ & $\begin{array}{c}\text { Государственные } \\
\text { бюджетные и автономные } \\
\text { вузы } \\
\end{array}$ & $\begin{array}{c}\text { Негосудар- } \\
\text { ственные } \\
\text { вузы }\end{array}$ \\
\hline Кулакова М.Н., 2012 & \multirow{3}{*}{\multicolumn{2}{|c|}{ Государственные вузы }} & \\
\hline Марков С.Н., 2012 & & & \\
\hline Сабырова Г.Ж., 2013 & & & \\
\hline $\begin{array}{l}\text { Боровская М.А., Задо- } \\
\text { рожная Е.К., Шевченко } \\
\text { И.К., } 2013 \\
\end{array}$ & \multirow{5}{*}{\multicolumn{2}{|c|}{ Вузы РФ }} & \\
\hline Григораш О.В., 2014 & & & \\
\hline Сабырова Г.Ж., 2014 & & & \\
\hline Сироткин Г.В., 2015 & & & \\
\hline $\begin{array}{l}\text { Методика мониторинга } \\
\text { Минобрнауки РФ, } 2016\end{array}$ & & & \\
\hline $\begin{array}{l}\text { Методика оценки качест- } \\
\text { ва финансового менедж- } \\
\text { мента Минобрнауки РФ }\end{array}$ & & $\begin{array}{c:c}\text { Государствен- } & \text { Государствен- } \\
\text { ные бюджет- } & \text { ные бюджет- } \\
\text { ные и авто- } & \text { ные и авто- } \\
\text { номные вузы, } & \text { номные вузы, } \\
\text { подведомст- } & \text { неподведомст- } \\
\text { венные Мин- } & \text { венные Мин- } \\
\text { обрнауки РФ } & \text { обрнауки РФ }\end{array}$ & \\
\hline
\end{tabular}

Условное обозначение: $\$ - не рассматриваются в методике оценки.

Следует отметить, что процесс обобщения объекта наблюдения в методиках оценки до вузов РФ был основан не на синтезе ранее существующих 
методик оценки отдельных типов вузов, а скорее на подмене объекта наблюдения в ранее существующих методиках оценки государственных вузов [15].

В настоящее время разработана и активно используется Минобрнауки РФ методика оценки качества финансового менеджмента, объектом наблюдения которой являются государственные бюджетные и автономные вузы, подведомственные Минобрнауки РФ $[17,18]$. Иных методик оценки, без учета производных от методики оценки качества финансового менеджмента Минобрнауки РФ, которые рассматривают в качестве объекта наблюдения государственные бюджетные и автономные вузы, не существует.

Таким образом, на текущий момент времени не существует методик оценки для объектов наблюдения: государственных казенных вузов; государственных бюджетных и автономных вузов, не подведомственных Минобрнауки РФ; негосударственных вузов (см. табл. 2).

2. Объект исследования методики оценки. В качестве объекта исследования методик оценки эффективности деятельности вузов национальной системы высшего образования РФ могут быть рассмотрены отдельные виды деятельности объекта наблюдения.

Таким образом, в соответствии с результатами ранее проведенного нами исследования можно утверждать, что в качестве объекта исследования методик оценки эффективности деятельности вузов национальной системы высшего образования РФ могут быть рассмотрены отдельные виды деятельности либо государственных казенных вузов, либо государственных бюджетных и автономных вузов, либо негосударственных вузов, либо более мелких в их составе групп.

В большинстве существующих на текущий момент времени методик оценки объекты исследования различных объектов наблюдения обобщаются, что недопустимо и приводит к ложным результатам.

Кроме того, финансовая деятельность как объект исследования часто рассматривается только в сочетании с хозяйственной деятельностью (финансово-хозяйственная деятельность).

Однако для осуществления контроля над реализацией изменений в социальных и экономических процессах вузов путем финансового регулирования этих процессов финансовую деятельность вузов необходимо рассматривать системно с экономической деятельностью (финансово-экономическая деятельность) $[19,20]$. При этом следует обратить внимание, что содержание финансово-экономической деятельности государственных казенных вузов, государственных бюджетных и автономных вузов и негосударственных вузов существенно различается, в связи с чем невозможно использовать для разных объектов наблюдения единые методы исследования. 
Определим финансово-хозяйственную деятельность вуза как деятельность вуза по реализации своих функций, увязанных с распределением и исполнением доведенного объема денежных средств и содержанием имущественного фонда (табл. 3).

\section{Объекты исследования в современных методиках оценки эффективности деятельности вузов}

\begin{tabular}{|c|c|c|c|}
\hline \multirow[b]{2}{*}{$\begin{array}{l}\text { Существующие } \\
\text { методики оценки }\end{array}$} & \multicolumn{3}{|c|}{ Допустимый уровень обобщения объекта наблюдения } \\
\hline & $\begin{array}{c}\text { Государственные } \\
\text { казенные вузы }\end{array}$ & $\begin{array}{c}\text { Государственные бюджет- } \\
\text { ные и автономные вузы }\end{array}$ & $\begin{array}{l}\text { Негосударствен- } \\
\text { ные вузы }\end{array}$ \\
\hline $\begin{array}{l}\text { Кулакова М.Н., } \\
2012\end{array}$ & \multirow{3}{*}{\multicolumn{2}{|c|}{$\begin{array}{c}\text { Финансово-хозяйственная деятельность } \\
\text { государственных вузов }\end{array}$}} & \\
\hline Марков С.Н., 2012 & & & \\
\hline $\begin{array}{l}\text { Сабырова Г.Ж., } \\
2013\end{array}$ & & & \\
\hline $\begin{array}{l}\text { Боровская М.А., } \\
\text { Задорожная Е.К., } \\
\text { Шевченко И.К., } \\
2013\end{array}$ & \multicolumn{3}{|c|}{ Финансово-хозяйственная деятельность вузов РФ } \\
\hline $\begin{array}{l}\text { Григораш О.В., } \\
2014\end{array}$ & \multicolumn{3}{|c|}{$\begin{array}{c}\text { Образовательная деятельность вузов РФ (для оценки используют- } \\
\text { ся показатели финансово-хозяйственной деятельностью) }\end{array}$} \\
\hline $\begin{array}{l}\text { Сабырова Г.Ж., } \\
2014\end{array}$ & \multicolumn{3}{|c|}{$\begin{array}{c}\text { Деятельность вузов РФ в комплексе (для оценки используются } \\
\text { показатели финансово-экономической деятельности) }\end{array}$} \\
\hline $\begin{array}{l}\text { Сироткин Г.В., } \\
2015\end{array}$ & \multirow{2}{*}{\multicolumn{3}{|c|}{$\begin{array}{c}\text { Деятельность вузов РФ в комплексе (финансово-экономическая } \\
\text { деятельность рассматривается как одно из направлений деятель- } \\
\text { ности вуза) }\end{array}$}} \\
\hline $\begin{array}{l}\text { Методика монито- } \\
\text { ринга Минобрнау- } \\
\text { ки РФ, } 2016\end{array}$ & & & \\
\hline $\begin{array}{l}\text { Методика оценки } \\
\text { качества финансо- } \\
\text { вого менеджмента } \\
\text { Минобрнауки РФ }\end{array}$ & & $\begin{array}{c}\text { Финансово- } \\
\text { хозяйственная } \\
\text { деятельность } \\
\text { государственных } \\
\text { бюджетных и } \\
\text { автономных ву- } \\
\text { зов, подведомст- } \\
\text { венные Минобр- } \\
\text { науки РФ }\end{array}$ & \\
\hline
\end{tabular}

Условное обозначение: $\square$ - не рассматриваются в методике оценки.

Финансово-эконолическую деятельность вуза определим как направление деятельности вуза, которое включает в себя следующие виды его деятельности в их взаимосвязи и взаимодействии: деятельность вуза по экономическому анализу тенденций и характера происходящих изменений в экономике на микро- и макроуровнях (ОКВЭД 72.20); деятельность вуза по 
оценке и анализу финансовой и экономической деятельности учреждения (ОКВЭД 72.20; 64); деятельность вуза по разработке, реализации и контролю мероприятий по формированию источников поступления денежных средств и направлений их расходования на кратко-, средне- и долгосрочные периоды времени (ОКВЭД 64).

Таким образом, на текущий момент времени не существует ни одной методики оценки вузов, способной комплексно оценивать финансовую деятельность вузов РФ, т.е. не существует методик оценки финансово-экономической деятельности (см. табл. 3):

- государственных казенных вузов;

- государственных бюджетных и автономных вузов;

- негосударственных вузов.

Bbывды. По результатам проведенного исследования логики методик оценки можно сформулировать следующие выводы:

1. Допустимым уровнем обобщения объекта наблюдения в методиках оценки является уровень обобщения, когда все вузы объекта наблюдения финансируются по одной модели финансирования.

2. Предельным уровнем обобщения объекта наблюдения в методиках оценки является уровень обобщения, когда множество вузов объекта наблюдения совпадает с множеством вузов объекта финансирования конкретной модели финансирования.

3. Запредельное обобщение объекта наблюдения в методиках оценки является причиной получения неполной и недостоверной информации в результате использования данной методики. Например, в основе методики оценки эффективности деятельности вузов М.Н. Кулаковой находится затратная модель финансирования, по которой финансируются только государственные казенные вузы. В качестве объекта наблюдения своей методики оценки М.Н. Кулакова определяет государственные вузы. В состав государственных вузов, помимо государственных казенных вузов, входят государственные бюджетные и автономные вузы, которые финансируются по иной модели финансирования и, следовательно, использование методики оценки М.Н. Кулаковой в отношении данных вузов недопустимо.

4. Чем выше уровень запредельного обобщения объекта наблюдения в методиках оценки, тем больше неполной и недостоверной информации исследователь получает в результате использования данной методики. Например, сравним две методики оценки эффективности деятельности вузов: методику оценки М.Н. Кулаковой и методику оценки М.А. Боровской, Е.К. Задорожной, И.К. Шевченко. В основе обеих методик оценки находится затратная модель финансирования, по которой финансируются только государственные казенные вузы. Однако объектом наблюдения методики оценки М.Н. Кулаковой являются государственные вузы РФ, а объектом наблюдения методики 
оценки М.А. Боровской, Е.К. Задорожной, И.К. Шевченко - вузы РФ. Следовательно, методика оценки М.Н. Кулаковой дает неполную и недостоверную информацию только по государственным бюджетным и автономным вузам, тогда как методика оценки М.А. Боровской, Е.К. Задорожной, И.К. Шевченко дает неполную и недостоверную информацию не только по государственным бюджетным и автономным вузам, но и по негосударственным вузам.

5. На текущий момент времени не существует методик оценки для объектов наблюдения: государственных казенных вузов; государственных бюджетных и автономных вузов, неподведомственных Минобрнауки РФ; негосударственных вузов.

6. В качестве объекта исследования методик оценки эффективности деятельности вузов могут быть рассмотрены отдельные виды деятельности либо государственных казенных вузов, либо государственных бюджетных и автономных вузов, либо негосударственных вузов, либо более мелких в их составе групп.

7. На текущий момент времени не существует методик оценки, в которых объектами исследования являются: финансово-экономическая деятельность государственных казенных вузов; финансово-экономическая деятельность государственных бюджетных и автономных вузов; финансово-экономическая деятельность негосударственных вузов.

Таким образом, для целенаправленного развития национальной системы высшего образования РФ необходимо наличие достоверной и полной информации о том, как финансовые механизмы влияют на изменения в социальных и экономических процессах вузов. Источником такой информации должен стать мониторинг финансово-экономической деятельности вузов РФ. На текущий момент времени в научной литературе РФ нет ни одной методики оценки, способной полно и достоверно оценить финансово-экономическую деятельность вузов РФ, так как методика оценки финансово-экономической деятельности вузов РФ должна представлять собой, как минимум, синтез трех методик оценки: методики оценки финансово-экономической деятельности государственных казенных вузов, методики оценки финансовоэкономической деятельности государственных бюджетных и автономных вузов и методики оценки финансово-экономической деятельности негосударственных вузов, которые также в настоящее время отсутствуют в научной литературе РФ. Поскольку в РФ большую часть составляют бюджетные и автономные вузы, в последующих работах мы разработаем методику по оценке их финансово-экономической деятельности.

\section{Список литературы}

1. Гусев Ю.В., Половова Т.А. Современные инструменты управления вузом // Гуманитарные науки и образование в Сибири. - 2015. - № 1 (19). C. $48-52$. 
2. Попов Д.В. Влияние глобализации на национальные системы высшего образования // Успехи современной науки. - 2016. - № 10 (4). - С. 84-89.

3. Мониторинг финансово-экономического состояния региона как условие развития институтов качественного экономического роста: моногр. / И.С. Ферова, И.С. Пыжев, И.А. Янкина, В.Н. Руцкий, Е.В. Бачерикова, Е.Н. Таненкова; Сиб. федер. ун-т. - Красноярск, 2016. - 160 с.

4. Попов Д.В. Модернизация системы финансирования учреждений высшего образования в Российской Федерации // Известия высших учебных заведений. Социология. Экономика. Политика. - 2017. - № 2 (53). - С. 101-109.

5. О внесении изменений в отдельные законодательные акты Российской Федерации в связи с совершенствованием правового положения государственных (муниципальных) учреждений: Федер. закон от 8 мая 2010 г. № 83-Ф3. - Доступ из справ.-правовой системы «КонсультантПлюс: Версия Проф» (дата обращения: 22.08.2018).

6. Кулакова М.Н. К вопросу о бюджетном финансировании деятельности вуза: современный подход // Территория новых возможностей. - 2012. № 2. - С. 124-129.

7. Марков С.Н. Методика оценки эффективности использования бюджетных расходов образовательными учреждениями // УЭкС. - 2012. № 7 (43). - С. 44.

8. Сабырова Г.Ж. Методика оценки эффективности использования бюджетных расходов образовательными учреждениями // Наука, новые технологии и инновации. - 2013. - № 7. - С. 122-125.

9. Захарова Е.Н., Гисина О.Г. Особенности формирования конкурентоспособности вуза как субъекта рынка образовательных услуг // Бизнес в законе. Экономико-юридический журнал. - 2013. - № 2. - С. 185-188.

10. Ивинский Д.В., Чепурова И.Ф. Предпринимательская деятельность вуза как элемент рыночной экономики // Социально-экономические явления и процессы. - 2014. - № 9 (3). - С. 31-36.

11. Боровская М.А., Задорожная Е.К., Шевченко И.К. Методическое обеспечение оценки финансово-экономической деятельности вуза // Университетское управление: практика и анализ. - 2013. - № 6 (88). - С. 27-33.

12. Григораш О.В. О необходимости изменения показателей оценки эффективности деятельности вузов // Экономика образования. - 2014. - № 4. C. 57-60.

13. Сабырова Г.Ж. Система сбалансированных показателей при оценке эффективности деятельности вуза // Известия вузов Кыргызстана. - 2014. № 11. - С. 103-106.

14. Сироткин Г.В. Новая структура системы оценки качества образования и эффективности деятельности для любого типа вуза в целом // Инновации в науке. - 2015. - № 5 (42). - С. 68-82. 
15. Об осуществлении мониторинга системы образования: Постановление Правительства РФ от 5 авг. 2013 г. № 662. - Доступ из справ.-правовой системы «КонсультантПлюс: Версия Проф» (дата обращения: 20.06.2018).

16. О проведении мониторинга эффективности образовательных организаций высшего образования: приказ Минобрнауки России от 18 марта 2016 г. № 244. - Доступ из справ.-правовой системы «КонсультантПлюс: Версия Проф» (дата обращения: 20.06.2018).

17. О формировании рейтинга качества финансового менеджмента образовательных организаций высшего образования, подведомственных Министерству образования и науки Российской Федерации: приказ Минобрнауки России от 17.08.2016 № 1052. - Доступ из справ.-правовой системы «КонсультантПлюс: Версия Проф» (дата обращения: 12.06.2018).

18. О внесении изменений в приказ Министерства образования и науки Российской Федерации от 17 августа 2016 г. № 1052 «О формировании рейтинга качества финансового менеджмента образовательных организаций высшего образования, подведомственных Министерству образования и науки Российской Федерации»: приказ Минобрнауки России от 05.09.2017 № 872. Доступ из справ.-правовой системы «КонсультантПлюс: Версия Проф» (дата обращения: 12.06.2018).

19. Попов Д.В. Эффективность финансово-экономической деятельности высшего учебного заведения // Вестник Томского государственного университета. Экономика. - 2017. - № 37. - С. 169-180.

20. Попов Д.В. Современные методики оценки эффективности деятельности вузов: сравнительный анализ // Вестник МГПУ. Экономика. - 2018. № 3 (17). - С. 64-77.

\section{References}

1. Gusev Iu.V., Polovova T.A. Sovremennye instrumenty upravleniia vuzom [Modern tools of higher school management]. Gumanitarnye nauki i obrazovanie v Sibiri, 2015, no. 1 (19), pp. 48-52.

2. Popov D.V. Vliianie globalizatsii na natsional'nye sistemy vysshego obrazovaniia [Influence of globalization on national higher education system]. Uspekhi sovremennoi nauki, 2016, no. 10 (4), pp. 84-89.

3. Ferova I.S., Pyzhev I.S., Iankina I.A., Rutskii V.N. [et al.]. Monitoring finansovo-ekonomicheskogo sostoianiia regiona kak uslovie razvitiia institutov kachestvennogo ekonomicheskogo rosta [Monitoring of financial and economic state of the region as a factor of development of institutions of high-quality economic growth]. Krasnoyarsk, Siberian Federal University, 2016, 160 p.

4. Popov D.V. Modernizatsiia sistemy finansirovaniia uchrezhdenii vysshego obrazovaniia v Rossiiskoi Federatsii [Modernization of the system of funding insti- 
tutions of higher education in the Russian Federation]. Izvestiia vysshikh uchebnykh zavedenii. Sotsiologiia. Ekonomika. Politika. 2017, no. 2 (53), pp. 101109.

5. O vnesenii izmenenii $\mathrm{v}$ otdel'nye zakonodatel'nye akty Rossiiskoi Federatsii $\mathrm{v}$ sviazi $\mathrm{s}$ sovershenstvovaniem pravovogo polozheniia gosudarstvennykh (munitsipal'nykh) uchrezhdenii [On amendments to certain legislative acts of the Russian Federation in connection with the improvement of the legal status of state (municipal) institutions]. Federal Law of May 8, 2010 no. 83-FZ. ConsultantPlus Legal reference system. Professional edition (accessed 22 August 2018).

6. Kulakova M.N. K voprosu o biudzhetnom finansirovanii deiatel'nosti vuza: sovremennyi podkhod [To the question of budgetary financing of higher school activities: Modern approach]. Territoriia novykh vozmozhnostei, 2012, no. 2, pp. 124-129.

7. Markov S.N. Metodika otsenki effektivnosti ispol'zovaniia biudzhetnykh raskhodov obrazovatel'nymi uchrezhdeniiami [Methods of evaluating the effectiveness of budget expenditures by education institutions]. UEkS, 2012, no. 7 (43), pp. 44.

8. Sabyrova G.Zh. Metodika otsenki effektivnosti ispol'zovaniia biudzhetnykh raskhodov obrazovatel'nymi uchrezhdeniiami [Methods of assessing effectiveness of budget expenditures by education institutions]. Nauka, novye tekhnologii i innovatsii, 2013, no. 7, pp. 122-125.

9. Zakharova E.N., Gisina O.G. Osobennosti formirovaniia konkurentosposobnosti vuza kak sub"ekta rynka obrazovatel'nykh uslug [Features of formation of competitiveness of higher education institution as a subject of education services market]. Biznes v zakone. Ekonomiko-iuridicheskii zhurnal, 2013, no. 2 , pp. 185-188.

10. Ivinskii D.V., Chepurova I.F. Predprinimatel'skaia deiatel'nost' vuza kak element rynochnoi ekonomiki [Business activity of higher education institution as element of market economy]. Sotsial'no-ekonomicheskie iavleniia i protsessy, 2014, no. 9 (3), pp. 31-36.

11. Borovskaia M.A., Zadorozhnaia E.K., Shevchenko I.K. Metodicheskoe obespechenie otsenki finansovo-ekonomicheskoi deiatel'nosti vuza [Methodology support for assessment of university financial and economic performance]. Universitetskoe upravlenie: praktika i analiz, 2013, no. 6 (88), pp. 27-33.

12. Grigorash O.V. O neobkhodimosti izmeneniia pokazatelei otsenki effektivnosti deiatel'nosti vuzov [On the need to change the indicators for assessing the effectiveness of the university]. Ekonomika obrazovaniia, 2014, no. 4, pp. 57-60.

13. Sabyrova G.Zh. Sistema sbalansirovannykh pokazatelei pri otsenke effektivnosti deiatel'nosti vuza [Balanced scorecard to assess the effectiveness of the university]. Izvestiia vuzov Kyrgyzstana, 2014, no. 11, pp. 103-106. 
14. Sirotkin G.V. Novaia struktura sistemy otsenki kachestva obrazovaniia $i$ effektivnosti deiatel'nosti dlia liubogo tipa vuza $v$ tselom [The new structure of the education quality assessment system and performance for any type of university as a whole]. Innovatsii v nauke, 2015, no. 5 (42), pp. 68-82.

15. Ob osushchestvlenii monitoringa sistemy obrazovaniia [On monitoring the educational system]. Government Decree of the Russian Federation of Aug. 5, 2013 no. 662. Consultant-Plus Legal Reference System. Professional edition (accessed 20 June 2018).

16. O provedenii monitoringa effektivnosti obrazovatel'nykh organizatsii vysshego obrazovaniia [On monitoring effectiveness of higher education institutions]. Order of the Ministry of Education and Science of the Russian Federation of March 18, 2016 no. 244. Consultant-Plus Legal Reference System. Professional edition (accessed 20 June 2018).

17. O formirovanii reitinga kachestva finansovogo menedzhmenta obrazovatel'nykh organizatsii vysshego obrazovaniia, podvedomstvennykh Ministerstvu obrazovaniia i nauki Rossiiskoi Federatsii [On formation of the quality rating of the financial management of educational institutions of higher education subordinate to the Ministry of Education and Science of the Russian Federation]. Order of the Ministry of Education and Science of Aug. 17, 2016 no. 1052. Consultant-Plus Legal Reference System. Professional edition (accessed 12 June 2018).

18. O vnesenii izmenenii $\mathrm{v}$ prikaz Ministerstva obrazovaniia i nauki Rossiiskoi Federatsii ot 17 avgusta 2016 g. № 1052 “O formirovanii reitinga kachestva finansovogo menedzhmenta obrazovatel'nykh organizatsii vysshego obrazovaniia, podvedomstvennykh Ministerstvu obrazovaniia i nauki Rossiiskoi Federatsii" [On amendments to the Order of the Ministry of Education and Science of the Russian Federation of Aug.17, 2016 no. 1052 "On formation of the quality rating of the financial management of educational institutions of higher education subordinate to the Ministry of Education and Science of the Russian Federation"]. Order of the Ministry of Education and Science of Sep. 09, 2017 no. 872. Consultant-Plus Legal Reference System. Professional edition (accessed 12 June 2018).

19. Popov D.V. Effektivnost' finansovo-ekonomicheskoi deiatel'nosti vysshego uchebnogo zavedeniia [Higher education institute effectiveness of financial and economic activities]. Vestnik Tomskogo gosudarstvennogo universiteta. Ekonomika, 2017, no. 37, pp. 169-180.

20. Popov D.V. Sovremennye metodiki otsenki effektivnosti deiatel'nosti vuzov: sravnitel'nyi analiz [Modern assessment methodology of universities' activity: Comparative analysis]. Vestnik MGPU. Ekonomika, 2018, no. 3 (17), pp. 64-77.

Оригинальность $87 \%$

Получено 21.09.2018 Принято 19.10.2018 Опубликовано 28.06.2019 


\title{
D.V. Popov
}

\section{LOGIC OF THE METHODS FOR EVALUATING UNIVERSITY PERFORMANCE}

\begin{abstract}
With the transition to a post-industrial society, a progress in the long-term socio-economic development of the country is largely determined by the results of higher education institutions and, above all, their financial-and-economic performance. Currently, there exist a number of methods to assess performance of the Russian universities, yet, none of them provides complete and accurate picture of their financial and economic condition. The reason, in our opinion, is rooted in an overgeneralized logic of methods for assessing the efficiency of the Russian universities, neglecting the specifics of universities of various types, the latter being determined by the difference in their financing models. The article analyzes the logic of methods of assessing performance of the Russian universities, that permitted to elucidate the ultimate and permissible levels of generalization of the object considered in the methods of evaluation and adequate objects for evaluation methods. As a result, we conclude that at present the Russian research literature does not encompass any method of evaluation that can fully and reliably assess the financial and economic activities of the Russian universities. In fact, such a method should integrate three evaluation techniques: one for state-owned public universities, one for state budgetary and autonomous universities, and one for non-state universities; all three are absent in the scientific literature of the Russian Federation.

Keywords: higher education, logic of assessment methodology, object of observation, object of research, monitoring of universities, financial regulation, efficiency of universities, budgetary institution, autonomous institution, financial and economic activity.
\end{abstract}

Dmitry V. Popov - Assistant Lecturer, Department of Financial Market and Institutions, Novosibirsk State University of Economics and Management, e-mail: dmit-popov@yandex.ru.

Received 21.09.2018 Accepted 19.10.2018 Published 28.06.2019 